\title{
Transcription of meiotic-like-pathway genes in Giardia intestinalis
}

\author{
Sandra P Melo, Vanessa Gómez, Isabel C Castellanos, Magda E Alvarado, Paula C Hernández, \\ Amanda Gallego, Moisés Wasserman/ ${ }^{1 /+}$
}

Laboratorio de Investigaciones Básicas en Bioquímica, Departamento de Química, Facultad de Ciencias, Universidad Nacional de Colombia, Bogotá, Colombia 'Laboratorio de Bioquímica, Instituto Nacional de Salud, Bogotá, Colombia

The reproductive mechanism of Giardia intestinalis, considered one of the earliest divergent eukaryotes, has not been fully defined yet. Some evidence supports the hypothesis that Giardia is an exclusively asexual organism with a clonal population structure. However, the high genetic variability, the variation in ploidy during its life cycle, the low heterozygosity and the existence of genes involved in the meiotic-like recombination pathway in the parasite's genome cast doubt on exclusively asexual nature of Giardia. In this work, semiquantitative RT-PCR analysis was used to assess the transcription pattern of three meiosis-like-specific genes involved in homologues recombination: $d m c 1$, hopl and spo11. The mRNAs were amplified during the parasite's differentiation processes, encystation and excystation, and expression was found at each stage of its life cycle. A semiquantitative assessment also suggests that expression of some of the genes is regulated during encystation process.

Key words: Giardia intestinalis - dmc1 - hop1 - spo11 - meiosis

Giardia intestinalis (syn. Giardia duodenalis, Giardia lamblia) is a protozoan parasite that causes giardiasis, one of the most common enteric diseases in the world. The parasite survives outside the host as a cyst, which is characterized by a rigid extracellular wall and the presence of four nuclei. Infection initiates by cyst ingestion, followed by excystation and release of four binucleated trophozoites per ingested cyst, which attach to and colonize the upper part of the small intestine (Bernarder et al. 2001). Some of the trophozoites undergo encystation, producing one cyst per differentiating trophozoite, and then are excreted to the environment through the faeces (Adam 2001). During vegetative growth the parasite divides by binary fission. Therefore, it is believed that Giardia reproduces in an exclusively asexual way and has a clonal population structure (Tibayrenc \& Ayala 2002). An organism of these characteristics and with a ploidy higher than one should have high allelic heterozygosity. However, it has been observed that Giardia has not only low allelic heterozigosity but also exhibits ploidy variation during the differentiation process that is reminiscent of meiosis (Bernarder et al. 2001). Although direct observation of sexual reproduction has not been described for Giardia, it has been proposed that this parasite might undergo rare meiotic-like events in the wild (Birky 2005, Cooper et al. 2007) or might undergo a parasexual phenomenon, a process where two cell nuclei merge without any sexual process, which unlike meiosis, is not accompanied by genome reduction and subsequent

Financial support: Colciencias (project 1101-0514649), Univ Nac de Colombia, Inst Nac de Salud

+ Corresponding author: mwassermannl@unal.edu.co

Received: 24 January 2008

Accepted: 12 June 2008 fusion of gametes from the same parent (Poxleitner et al. 2008). Parasexuality is supported by the observations of nuclei fusion in the Giardia cyst (karyogamy) together with a phylogenomic analysis of the Giardia sequenced genome that revealed genes associated with homologous recombination (Ramesh et al. 2005). Homologues recombination is one of the most important consequences of meiosis and has been rated by some authors as the essence of sex (Villenueve \& Hillers 2001). While in mitotically dividing cells, recombination is used to repair lesions in DNA from problems in replication or DNA damage in sister chromatids, in meiosis, recombination is initiated by the intentional introduction of meiosis-specific double strand breaks between nonsister chromatids creating genetic variation.

In this work we have assessed the presence, and analyzed the transcription pattern, of three meiotic-likespecific genes essential for homologues recombination: spoll (sporulation protein), hop1 (homolog pairing), and dmcl (disrupted meiotic cDNA) through the Giardia cell cycle. The Spoll protein has the catalytic site required for DNA breaking (Keeney et al. 1997); hopl binds at the sites where rupture occurs protecting DNA against exonucleases and modulating the beginning of the process (Kironmai et al. 1998); and Dmcl mediates homologue duplex DNA crossover (Shinohara \& Shinohara 2004).

\section{MATERIALS AND METHODS}

Bioinformatic analysis - Amino acid sequences of Spo11, Hop1 and Dmc1 from different organisms were taken from the NCBI protein database. For each protein a consensus sequence was obtained using the program MULTALIN (http://npsa-pbil.ibcp.fr/cgi-bin/align-multalin.pl) (Combet et al. 2000), and compared against the Giardia genome (http://www.ncbi.nlm.nih.gov/sutils/ genom tree.cgi?organism=euk) using tBlastn. For each identified gene, oligonucleotides were designed (Table) and used for RT-PCR reactions. 
TABLE

Oligonucleotides used to amplify the genes in the study

\begin{tabular}{|c|c|c|c|c|}
\hline $\begin{array}{l}\text { Accession } \\
\text { numbers }\end{array}$ & Gene & Sense Primer & Antisense Primer & $\begin{array}{r}\text { Expected } \\
\text { size (bp) }\end{array}$ \\
\hline AF485825 & spo11 & 5'TGCTTGGGAACTGTACTA3' & 5'CTCTTGTCCAAGAATGGT3' & 607 \\
\hline AF485827 & hop1 & 5'TCATCGAGAGCTACAACT3' & 5'GACGACATTGAGGACACT3' & 586 \\
\hline AF485823 & $\mathrm{dmcl} A$ & 5'AGCGAGCTCCTGCGAATGTATGTATCA3' & 5'AGCTCTAGAGATCTAACTTGTACCGCT3' & 627 \\
\hline AF485824 & $\mathrm{dmcl} B$ & 5'GTAGAGCTCCTGCTGAAGTTAGTGAGA3' & 5'CATTCTAGAGGTTGCGACAGATAAGAT3' & 307 \\
\hline
\end{tabular}

Cell culture and in-vitro differentiation - G. intestinalis trophozoites (WB, clone C6) were cultured in Diamond TYI-S-33 pH 7.0 medium supplemented with 10\% bovine serum and $0.5 \mathrm{mg} / \mathrm{ml}$ bovine bile (bb) at $34^{\circ} \mathrm{C}$ in borosilicate tubes (Keister 1983). For in vitro encystation, trophozoites were cultured at $37^{\circ} \mathrm{C}$ in TYI-S-33 pH 7.8 medium, supplemented with $5.0 \mathrm{mg} / \mathrm{ml}$ bb (Kane et al. 1991). Samples were harvested $0,0.5,3,6,12$, and $24 \mathrm{~h}$ after stimulus. The efficiency of encystation in these experiments was $40 \%$, calculated as: $\%$ encystation $=$ $(\mathrm{C} / \mathrm{T}) \mathrm{X} 100$, where $\mathrm{C}$ is cysts and $\mathrm{T}$ is trophozoites at $0 \mathrm{~h}$. In vitro excystation was performed using the two phase method reported by Bingham and Meyer (1979). The cysts were obtained from faecal samples and purified as previously described (Alvarado \& Wasserman 2006). Briefly, cysts were incubated at $37^{\circ} \mathrm{C} / 1 \mathrm{~h}$ at $\mathrm{pH} 1.6$ in a medium containing $25 \mathrm{mM} \mathrm{NaHCO}_{3}, 12 \mathrm{mM} \mathrm{KCl}, 40 \mathrm{mM}$ $\mathrm{NaCl}$, and $12 \mathrm{mM} \mathrm{CaCl}_{2}$ (acid induction, or phase I), and then incubated at $37^{\circ} \mathrm{C} / 1 \mathrm{~h}$ in TYI-S-33 medium (excystation or phase II). Parasites were harvested before stimulus, after acid induction, and after excystation. The efficiency of excystation was typically $30 \%$, calculated as: $\%$ excystation $=[(\mathrm{T} / 2)+\mathrm{E} /(\mathrm{T} / 2)+\mathrm{E}+\mathrm{C}] \times 100$, where $\mathrm{T}$ is trophozoites, $\mathrm{E}$ is excyzoites, and $\mathrm{C}$ is cysts.

Detection of $m R N A$ - Total RNA was isolated from $G$. intestinalis at the indicated stages of differentiation (encystation and excystation) using the commercial kit SNAPTM Total RNA (Invitrogen). Semiquantitative reverse transcription nested polymerase chain reactions (RT-PCR) were done by duplicate. In each case, the quantity of RNA used was such that the changes in product were proportional to the template concentration. RT-PCR reactions contained $0.5 \mu \mathrm{M}$ of oligonucleotides, $0.5 \mathrm{mM}$ of dNTP's, $3.0 \mathrm{mM}$ of $\mathrm{MgCl}_{2}$, $1 \mathrm{U}$ of M-MLV-RT (Promega) and $0.5 \mathrm{U}$ of Taq polymerase in a buffer containing $50 \mathrm{mM}$ Tris- $\mathrm{HCl}$ at $\mathrm{pH} 8.3,75 \mathrm{mM} \mathrm{KCl}, 3 \mathrm{mM} \mathrm{MgCl}$ and $10 \mathrm{mM}$ DTT. Reverse transcription was performed according to manufacturer's instructions. cDNA was amplified with the following program: $94^{\circ} \mathrm{C} / 5 \mathrm{~min}, 30$ cycles at $94^{\circ} \mathrm{C} /$ $45 \mathrm{~s}, 55^{\circ} \mathrm{C} / 45 \mathrm{~s}, 72^{\circ} \mathrm{C} / 1 \mathrm{~min}$ and $72^{\circ} \mathrm{C} / 7 \mathrm{~min}$. DNA absence verification for each RNA preparation was assessed using RNA as a template instead of cDNA. The dmc1-B and dmcl-A gene transcripts were amplified on $10 \mathrm{ng}$ of RNA during both encystation and excystation, while $70 \mathrm{ng}$ of RNA from the same samples had to be used to observe well-defined bands of the spoll and hopl genes during encystation and $50 \mathrm{ng}$ for excystation. Products were analyzed by agarose electrophoresis and quantified by densitometry. The housekeeping gene ubiquitin was used as a loading control (Gallego et al. 2007).

\section{RESULTS}

Bioinformatic analysis - tBlastn analysis allowed identification of one homolog of spol1, one of hop1, and two homologues of dmc1, referred as dmclA and dmc1B, which correspond to the same ones reported as putative in the GenBank (Accession numbers AF485825, AF485827, AF485823, AF485824, respectively).

Detection of $m R N A$ s during the life cycle of $G$. intestinalis - Semi-quantitative RT-PCR on RNA extracted at different times during encystation and excystation of Giardia was performed to assess the transcription of dmc1B, dmclA, spoll and hopl genes. Fig. 1 shows the level of the mRNAs relative to ubiquitin during the encystation process as analyzed by densitometry on the bands obtained from RT-PCR (inset). Band intensity

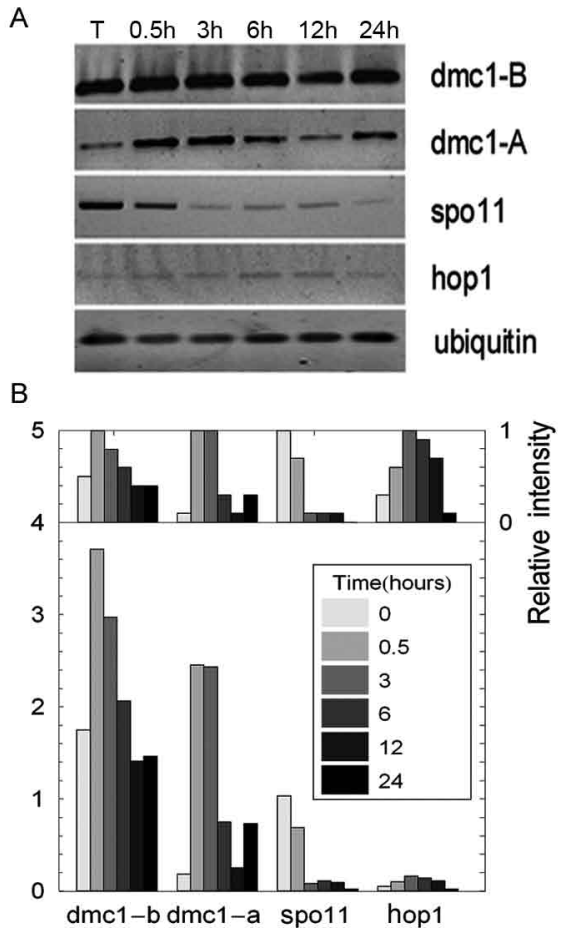

Fig. 1: transcription pattern of dmclb, dmcla, spoll and hop1 genes during Giardia intestinalis encystation. Semiquantitative RT-PCR analysis was done as described. A: amplified products are shown after electrophoresis on a BrEtd-stained agarose gel. Total RNA obtained from cells before stimulus (trophozoites, T) and 0.5, 3, 6, 12 and $24 \mathrm{~h}$ after stimulus; B: densitometric analysis were performed using the ImageJ software (Wayne Rasband, National Institutes of Health, USA). Top panel shows relative values respect to the highest value for each gene. Bottom panel shows normalized values respect to ubiquitin. 
A

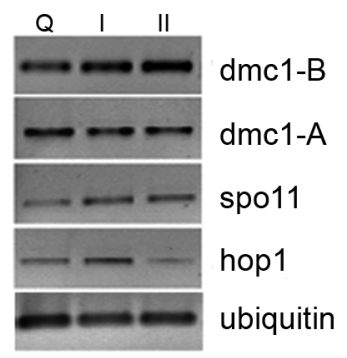

B

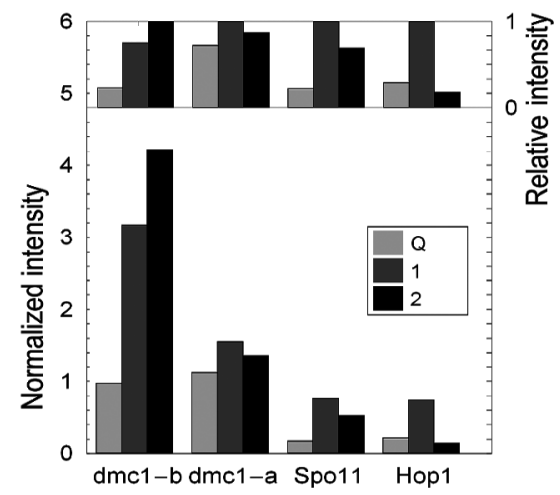

Fig. 2: transcription pattern of dmclb, dmcla, spoll and hopl genes during Giardia intestinalis excystation. Semiquantitative RT-PCR analysis was done as described. A: amplified products using total RNA as a template. Lanes - Q: product generated on RNA obtained from cysts before stimulus; I: product generated from RNA extracted from cells after the acid stage of the process; II: product generated from RNA extracted from cells after the second phase; B: densitometric analysis were performed using the ImageJ software (Wayne Rasband, National Institutes of Health, USA). Top panel shows relative values respect to the highest value for each gene. Bottom panel shows normalized values respect to ubiquitin.

varies among transcripts, reflecting different mRNA abundance at time zero (trophozoites) and during the encystation process; spol1 and hop1 are the less abundant transcripts as indicated by the fact that even using seven times the amount required to amplify the other genes, their intensity was still low. To fully appreciate changes at the transcript level, intensity values were normalized to the highest value for each gene (inset on top column charts). This analysis shows that dmc1B y hopl exhibit a similar pattern. After 30 min of encystation stimuli transcript levels increase two fold relative to trophozoites that have not been stimulated to encyst (time zero). After $6 \mathrm{~h}$, levels of transcripts are down-regulated to reach levels similar to those at time zero, in dmclb's case, or levels three fold lower to time zero, in hopl's case. dmclA and spol1 show dramatic changes at the transcript level. While dmc1A levels increase 10 fold after $30 \mathrm{~min}$ of encystation and are maintained after $3 \mathrm{~h}$; after $6 \mathrm{~h}$, levels return to their time zero value. On the other hand, spoll mRNA levels decrease markedly at $3 \mathrm{~h}$ of encystation. Fig. 2 shows a similar analysis but for the excystation process. A similar pattern is observed for dmclA and dmclB: a stepped increase at the transcript level during the phase I and phase II of excystation respect to the initial point (cysts). On the other hand, hop1 and spoll exhibit a marked decrease during phase II. Observed variations at transcript level might indicate differential regulation of these genes during the life cycle of the parasite.

\section{DISCUSSION}

It has been recently suggested that karyogamy during encystation together with homologous recombination and/or gene conversion driven by meiotic recombination genes could provide a mechanism by which Giardia maintains low levels of allelic heterozygosity (Poxleitner et al. 2008). Nuclei fusion has been physically observed through transmission electron micrographs (Poxleitner et al. 2008), and the presence of meiotic recombinant genes has been detected in phylogenomic studies (Ramesh et al. 2005). In this report we have shown that three of the eukaryotic meiotic-like recombination core genes, dmc1, spoll and hopl are present not only in the Giardia genome but are also being differentially transcribed during its life cycle suggesting a critical function in Giardia's differentiation process.

We have identified two homologues of the dmcl gene, called dmclA and dmc1B, and one homolog of spoll and hopl genes. The gene labelled as dmclB has the same sequence as another gene reported in the GenBank as Rad51, a gene whose product is involved in DNA repair during mitosis and meiosis. Phylogenomic studies (Ramesh et al. 2005) suggested that dmc1B belongs to the dmc1 family and not to that of rad51. This interpretation points to a probable divergence between the two families later during the evolutionary process and, therefore suggests that Giardia does not possess a homologue of Rad51. However, we found a very substantial difference in the transcription pattern of these two genes, which might indicate that dmc1B, whose mRNA is transcribed almost constitutively during the life cycle of Giardia, has a more general role, similar to that of $\operatorname{Rad} 51$.

Although mRNA levels of spol1 and hop1 are substantially lower, their strong regulation might indicate an important role of the product of these genes during early encystation and early excystation. Accordingly, dmclA also is strongly induced during excystation, and remains high while spol1 and hop1 are being transcribed. It was recently shown that during encystation genetic material exchange occurs between and within two nuclei of the Giardia cyst (Poxleitner et al. 2008). Transcription of dmc1A, spo11 and hop1 might facilitate this process during early encystation. However, this might not be limited to only encystation, since a similar phenomenon was observed during excystation.

Since it is believed that eukaryotic meiosis machinery initially evolved from genes involved in DNA repair (Villenueve \& Hillers 2001), the existence of homologous recombination genes in the Giardia genome suggests that such phenomenon might occur in this parasite, and might account for the high allelic heterozigosity observed in Giardia. Alternatively, these genes may play a different role in primitive organisms such as Giardia (Morrison et al. 2007), while function specialization occurred later during evolution. In either case, a deeper understanding of the function of these genes will give insight into the evolution of sex and the biology of Giardia. 


\section{REFERENCES}

Adam RD 2001. Biology of Giardia lamblia. Clin Microbiol Rev 14: $447-475$.

Alvarado M, Wasserman M 2006. Quick and efficient purification of Giardia intestinalis cysts from fecal samples. Parasitol Res 99: 300-302.

Bernarder R, Palm J, Svärd S 2001. Genome ploidy in different stages of the Giardia lamblia life cycle. Cell Microbiol 3: 55-62.

Bingham AK, Meyer EA 1979. Giardia excystation can be induced in vitro in acidic solutions. Nature 277: 301-302.

Birky CW 2005. Sex: is Giardia doing it in the dark? Curr Biol 15: R56-R58.

Combet C, Blanchet C, Geourjon C, Deléage G 2000. NPS@: Network Protein Sequence Analysis. Trends Biochem Sci 25: 147-150.

Cooper MA, Adam RD, Worobey M, Sterling CR 2007. Population genetics provides evidence for recombination in Giardia. Curr Biol 17: 1984-1988.

Gallego E, Alvarado ME, Wasserman M 2007. Identification and expression of the protein ubiquitination system in Giardia intestinalis. Parasitol. Res 101: 1-7.

Kane A, Ward G, Keush T, Pereira M 1991. In vitro encystation of Giardia lamblia: large-scale production of in vitro cyst and strain and clone differences in encystation efficiency. J Parasitol 77: 974-981.

Keeney S, Giroux CN, Kleckner N 1997. Meiosis-specific DNA double-strand breaks are catalyzed by Spo11, a member of a widely conserved protein family. Cell 88: 375-384.
Keister DB 1983. Axenic culture of Giardia lamblia in TYI-S-33 medium supplemented with bile. Trans $R$ Soc Trop Med Hyg 77: 487-488.

Kironmai KM, Muniyappa K, Friedman DB, Hollingsworth NM, Byers B 1998. DNA-binding activities of Hopl protein, a synaptonemal complex component from Saccharomyces cerevisiae. Mol Cell Biol 18: 1424-1435.

Morrison H, McArthur A, Gillin F, Aley S, Adam R, Olsen G, Best A, Cande W, Chen F, Cipriano M, Davids B, Dawson S, Elmendorf H, Hehl A, Holder M, Huse S, Kim U, Lasek-Nesselquist E, Manning G, Nigam A, Nixon J, Palm D, Passamaneck N, Prabhu A, Reich C, Reiner D, Samuelson J, Svard S, Sogin M 2007. Genomic minimalism in the early diverging intestinal parasite Giardia lamblia. Science 317: 1921-1926.

Poxleitner MK, Carpenter ML, Mancuso JJ, Wang C Jr, Dawson SC, Cande WZ 2008. Evidence for karyogamy and exchange of genetic material in the binucleate intestinal parasite Giardia intestinalis. Science 319: 1530-1533.

Ramesh MA, Malik S, Logsdon JM 2005. A phylogenomic inventory of meiotic genes: Evidence for sex in Giardia and an early eukaryotic origin of meiosis. Curr Biol 15: 185-191.

Shinohara A, Shinohara M 2004. Roles of RecA homologues Rad51 and Dmcl during meiotic recombination. Cytogenet Genome Res 107: $201-207$

Tibayrenc M, Ayala FJ 2002. The clonal theory of parasitic protozoa: 12 years on. Trends Parasitol 18: 405-409.

Villeneuve AM, Hillers KJ 2001. Whence meiosis? Cell 106: 647-650. 